\title{
Physicochemical Properties of Chemical Pollutants Available in Food Contact Materials (FCM)
}

\author{
Joanna Farhat ${ }^{1,2}$, Joseph $\mathrm{Saab}^{1, *}$, Juliette Stephan ${ }^{3}$, Antonio Kashanna ${ }^{l}$, Christelle \\ Goutaudier $^{2}$ and Ilham Mokbel $^{2}$ \\ ${ }^{1}$ Holy Spirit University of Kaslik, Faculty of Sciences, Dept. Chemistry Biochemistry, Group ThEA- \\ Thermodynamic Phase Equilibria and Analysis, B. P. 446 Jounieh, Lebanon \\ ${ }^{2}$ Univ Lyon, Université Claude Bernard Lyon 1, CNRS, Laboratoire des Multimatériaux et Interfaces, \\ UMR 5615, F-69622 Lyon, France \\ ${ }^{3}$ Lebanese University, Faculty of Sciences, Dept. Chemistry Biochemistry, Group ASP-Multiphases \\ Systems Analysis, Fanar, Beirut, Lebanon
}

\begin{abstract}
Health and welfare of population are priority reasons to study the toxic effects of chemical pollutants. These effects can directly produce deterioration of health or can cause less healthful environment toxicity and restricting food production. Thereby, preventing such a consequence is important for human health risk assessment. In recent times, the use of recycled materials for packaging has undeniably been intensified. Nevertheless, recycling systems could not effectively eliminate the potential effect of chemical pollutants (alkyl phenol, phthalates, aldehydes, etc.) existent in such packages. The migration process and/or the ability of these pollutants to be absorbed into the recycled material, subsequently released by the packaging material, and then trapped by the matrices they contain, has become a potential source of exposure to consumers. This process is controlled by the nature of the packaging, time, temperature, and the physicochemical properties of the contaminant. The literature suffers from a lack of data related to the physicochemical (aqueous solubility, vapor pressure, Henry's constant, etc...) of these contaminants. In this work, we are going to describe the experimental devices used for aqueous solubility, vapor pressure and octanol/water partition coefficient determination.
\end{abstract}

\section{Introduction}

Industrial and technology fields use hundreds of chemicals within the production process wherever large amounts of those contaminated chemicals escape or are non-intentionally introduced into the surroundings.

The physicochemical properties of these chemical pollutants as well as their transports, degradations processes and biotransformation mechanisms, affects the behavior, fate and subsequently the harmful effects of these chemicals. 
Therefore, new rules are enforced to shift toward eco-friendly industries and study the surroundings chemodynamic of various chemical pollutants rising the protection of human health and therefore the environment through the higher and earlier qualification of the fundamental properties of chemical substances [1].

In the area of food contact materials (FCM), there are different interaction mechanisms which could potentially affect the integrity of the food and/or polymer. These mechanisms can be divided into permeation, sorption and migration. The process whereby food chemicals transfer from FCM into foodstuffs is known as migration. Chemical migration depends mostly on temperature, time, food content (e.g., fatty food, etc.) and FCM (e.g., organic or inorganic packaging, etc.), as well as physicochemical properties of contaminants available in FCM. Since the migration phenomena of contaminants from the food packaging into food matrices is little or not known and would dictate the exposure pathway of xenobiotic to the bio-receptor. The prediction of food contaminants transport through physicochemical properties determination can participate within the progress of predictive models on behavior and fate of the chemicals in regard to human exposure. On the far side this, it affords info that might be used to develop procedures of producing, use, and disposal that may cut back environmental pollution and risk exposure [2].

Chemical pollutants represent difficulties for the experimental calculation of their properties, specifically for low aqueous solubility (mole fraction lower than $10^{-4}$ ), a low vapor pressure (less than $10^{-2} \mathrm{~Pa}$ ), and a high lipophilicity (log Ko/w beyond 3 ).

With this aim, we studied the temperature dependence of the aqueous solubility of dipentylphthalate [298.15-303.15 k] using "generator column-on-line solid phase extraction method" [3]. Therefore, the validation of the inert gas saturation method for vapor pressure measurement of higher molecular weight materials was carried out for phenanthrene at $372.51 \mathrm{~K}$. The shake-flask method for octanol-water partition of heavy organic compounds, having $\log \mathrm{Ko} / \mathrm{w}>4$, is validated by studying the anthracene at $298.15 \mathrm{~K}$.

\section{Materials \& Methods}

\subsection{Aqueous solubility}

\subsubsection{Experimental part}

The water solubility of dipentylphthalate (DnPeP) (CAS=131-18-0, MW= $306.402 \mathrm{~g}$ mol1) is measured between $298.15 \mathrm{~K}$ and $303.15 \mathrm{~K}$ by using generator column-on-line solid phase extraction technique.

This method is based on the saturation of a known quantity of water flowing through a cell packed with a stationary phase (Chromosorb W 60/80 mesh) previously coated by the suitable organic solute ( $>5 \%$ by mass).

The generator column and the preheating coil are placed in a chromatographic oven. The heated and saturated water stream passes through an extraction column to trap the solute. The apparatus used in our laboratory is presented in Figure 1 where temperature varies within $\pm 0.05^{\circ} \mathrm{C}$ by means of a PID temperature controller. A low pressure pump maintains a regular and low stream $(0.1 \mathrm{ml} / \mathrm{min})$ of ultra-pure water through the saturation cell in order to achieve the equilibrium between phases. The preheating coil guarantees that before entering the generator column, all the quantity of water has gained the consigned temperature. The heated water passes through the saturation cell exiting the preheating coil and passes through the extraction column where the solution is subsequently trapped.

The solubility of DnPeP decreases and its affinity to the extraction column increases passing through the refrigerator. The solute free water is collected and weighed. Using 
methanol, the recuperation of the solute from the extraction column is done. The methanol is held outside the generator column thanks to the "T" switch positioned on the saturation cell. The final step will be the extraction of the solute by the adequate solvent, in order to be analyzed by HPLC-DAD

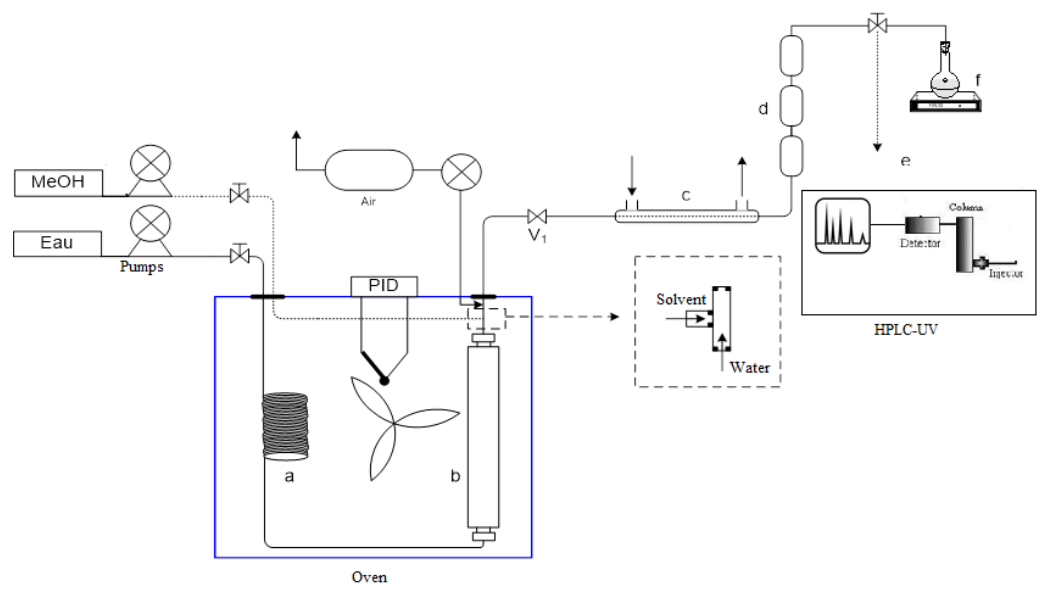

Fig. 1. Generator column-on-line solid phase extraction technique for low aqueous solubility measurement

(a) : Preheating coil ; (b) : Saturation Cell ; (c) : Refrigerant ; (d) : Extraction Column ; (e) : HPLC-DAD Analysis ; (f) : Weighing balance

\subsubsection{Aqueous solubility determination}

The aqueous solubility of DnPeP is calculated in mole fraction (Xsol) using the following equation 1:

$$
X_{\text {solute }}=\frac{n_{\text {solute }}}{\left(n_{\text {solute }}+n_{\text {water }}\right)}
$$

With "Xsol" the solubility expressed in mole fraction and " $n$ " the quantity of substances in mole.

The trend in figure 2 confirms that DnPeP's water solubility, increase with temperature accordingly to literature in the interval of $10^{-8}$. 


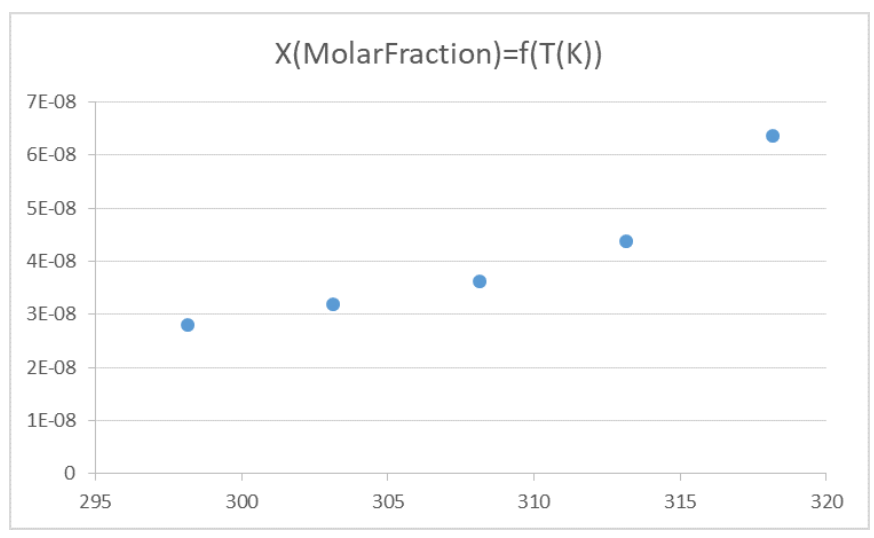

Fig. 2. Aqueous solubility of DnPeP between $298.15 \mathrm{~K}$ and $303.15 \mathrm{~K}$ in mole fraction in function with temperature in Kelvin.

\subsection{Vapor pressure}

\subsubsection{Experimental part}

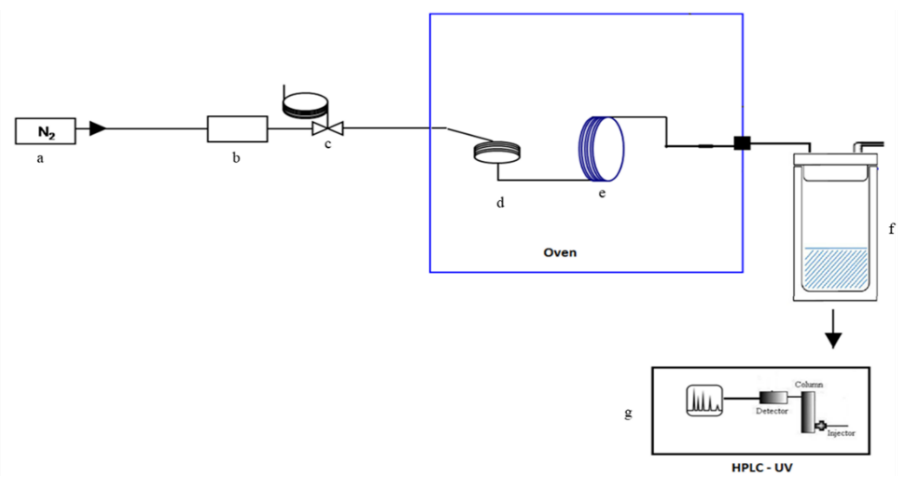

Fig. 3. Dynamic gas saturation method for low vapor pressure measurements.

(a) Gas Cylinder; (b) Flowmeter; (c) Valve; (d) Preheating Coil; (e) Saturator; (f) Cooling System; (g) HPLC-UV Analysis

Measurements of very low vapor pressures (below $1 \mathrm{~Pa}$ ), which is the case of high molecular weight materials, could not be carried out the static method.

These limitations necessitate the use of indirect vapor pressure measurement techniques such as inert gas saturation method. This apparatus promises reliable measurements within a large pressure interval ranging from $10^{-5} \mathrm{~Pa}$ to $10^{3} \mathrm{~Pa}$. Dynamic gas saturation technique relies on the gas saturation methodology employed in absolute mode. It is composed of two compartments as shown in figure 3. The sampling part consists of an equilibrium oven containing the cell saturator. The latter being stainless-steel columns full of porous support (Chromosorb NAW 60/80 mesh) coated with the studied compound.

The second part could be a cooler system where the vapor of the cell substance is condensate. Once equilibrium is reached, the compound is carried from the saturator by the chemical element N2 into a stainless-steel trap. Once the amount is enough to be quantified, 
the elution takes place to calculate the vapor pressure by HPLC-DAD analysis using the external calibration method [4].

\subsubsection{Vapor pressure determination}

The calculation of the vapor pressure is based on the application of the ideal gas law:

Where,

$$
P_{i}=\frac{n_{i} R T}{V_{i}}
$$

Pi: partial pressure of compound i $(\mathrm{Pa})$.

Vi: volume of the vapor phase containing the compound $\mathrm{i}\left(\mathrm{m}^{3}\right)$.

ni: amount of compound i in mole (mole).

$\mathrm{R}$ : gas constant $\mathrm{R}=8.314 \mathrm{~J} \mathrm{~K}^{-1} \mathrm{~mol}^{-1}$.

$\mathrm{T}$ : Temperature in Kelvin $(\mathrm{K})$.

$$
V_{i}=Q \cdot t
$$

Where,

t: trapping time (s).

Q: gas flow $\left(\mathrm{m} 3 \cdot \mathrm{s}^{-1}\right)$.

The validation of the experimental vapor pressure of phenantherene C14H10 $(\mathrm{MW}=178.23 \mathrm{~g}$ mol-1) at $372.51 \mathrm{~K}$, a recommended reference compound by IUPAC, showed a low relative standard deviation equal to $0.4 \%$ (table 1 ).

\begin{tabular}{|c|c|c|c|c|c|}
\hline Experiment & Temperature (K) & Vapor pressure (Pa) & Mean Vp (Pa) & SD & RSD (\%) \\
\hline 1 & \multirow{6}{*}{372.51} & 26.3 & \multirow{6}{*}{26.4} & \multirow{6}{*}{0.108} & \multirow{6}{*}{0.4} \\
\hline 2 & & 26.3 & & & \\
\hline 3 & & 26.4 & & & \\
\hline 4 & & 26.4 & & & \\
\hline 5 & & 26.5 & & & \\
\hline 6 & & 26.6 & & & \\
\hline
\end{tabular}

Table 1. Vapor pressure of Phenanthrene at $372.51 \mathrm{~K}$.

\subsection{Octanol/water partition coefficient}

\subsubsection{Experimental part}

In this part, the octanol/water partition constant $\mathrm{KO} / \mathrm{W}$ is done with the shake-flask technique in static mode. The noctanol pre-saturated water is brought into double coated flask with a magnetic stirrer, then the water pre-saturated noctanol part containing the solute is poured rigorously so as to avoid emulsion formation as way as possible.

This device consisted of three thermostated double jacket reactors with a thermocouple placed in the cell allowing the temperature measurement of the solution (Figure 4). Thus, temperature within $\pm 0.1 \mathrm{~K}$ was measured. These cells were placed in series to control measurement reproducibility and to check the balance between phases of mass transfer.

We note that at transfer equilibrium, the dissolved amount of anthracene in the solvents (presaturated) should not exceed $50 \%$ of the solubility limits in both phases. In addition, 
each cell was equipped with an air valve to create the required pressure and pre-concentrate the aqueous phase analyte on a C8 column.

The exit valve was fitted with a double drain sampling line at the bottom of the cell. The first (in the bottom) was aimed at draining the aqueous phase while the second was targeted to the organic phase. We installed two sampling valves downstream from these two drains, which were recommended for their reduced dead volume. This feature was required to reduce the risk of adsorption of the analyte in the valves and the draining lines.

For anthracene $\mathrm{C} 14 \mathrm{H} 10$ (MW=178.23 g mol-1) analysis, water part is taken and seeped into C-8 extraction column where analyte is retained. Then the substance is eluted by methanol and quantified by HPLC-DAD.

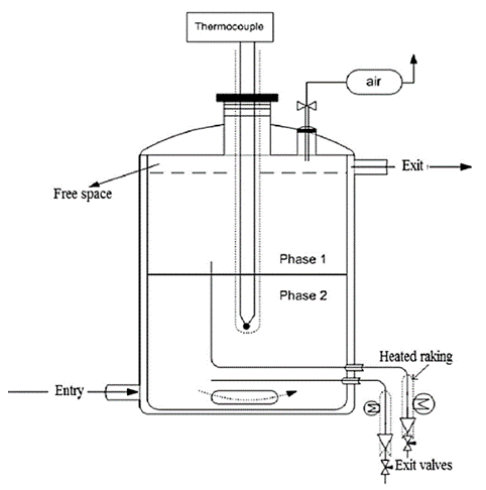

Fig. 4. Shak-flask method

\subsubsection{Octanol/water partition coefficient}

The Octanol/Water partition constant is calculated using equation 4:

$$
K_{\text {ow }}=\frac{C_{i}^{O}}{C_{i}^{W}}
$$

The validation of $\mathrm{Ko} / \mathrm{w}$ of anthracene is summarized in table 2 . The mean value of $\log \mathrm{Ko} / \mathrm{w}$ was 4.69 with a relative deviation smaller than $0.6 \%$ compared to the literature $[5]$.

Table 2. Experimental optimization for $\log \mathrm{K}_{\mathrm{o} / \mathrm{w}}$ measurements of anthracene at $298.15 \mathrm{~K}$.

\begin{tabular}{|c|c|c|c|c|c|c|c|}
\hline Experiment & $\begin{array}{c}\text { Stirring } \\
\text { time } \\
\text { between } \\
\text { phases } \\
\text { (hour) }\end{array}$ & $\begin{array}{c}\text { Vortex } \\
\text { (cm) }\end{array}$ & $\begin{array}{c}\text { settle time } \\
\text { before } \\
\text { sampling } \\
\text { (h) }\end{array}$ & $\begin{array}{c}\text { log } \\
\mathbf{K o} / \mathbf{w}\end{array}$ & $\begin{array}{c}\text { Mean } \\
\mathbf{l o g} \\
\mathbf{K o} / \mathbf{w}\end{array}$ & $\begin{array}{c}\text { RSD } \\
\mathbf{( \% )}\end{array}$ & $\begin{array}{c}\text { Relative } \\
\text { deviation } \\
\text { with the } \\
\text { literature } \\
\text { (\%) }\end{array}$ \\
\hline 1 & 18 & 1 & 6 & 4.69 & & \multirow{2}{*}{4} & 0.21 \\
\hline 2 & 18 & 1 & 6 & 4.67 & & \\
\hline 3 & 18 & 1 & 6 & 4.70 & & & 0.06 \\
\hline
\end{tabular}




\section{Conclusion}

Through the outputs (short-term run) of this project, we responded to three parameters among the twelve, which are required by the European Regulation REACH Registration, Evaluation and authorization of Chemicals).

Nevertheless, the target (long-term run) is to enhance the protection of human health and therefore the surroundings through the higher and earlier identification of the intrinsic properties of chemical substances contained in FCMs.

The acquired data could be used by the scientific community, the environmental researchers and by the national and international authorities in order to assess the health risks of these molecules by the time of its identification in food packaging (preconsumption) based on the migration process.

Therefore, this process will scientifically support the decision of Food Contact Material laboratories as well as the local packaging companies to correlate faster the package's type to the adequate food content.

The authors would like to thank the Higher Center for Research-USEK (HCR-USEK) and the Lebanese National Council for Scientific Research in Lebanon (CNRS-L) for their ongoing financial support.

\section{References}

[1] Freed, V. H., Chiou, C. T. \& Haque, R., Environ. Health Perspec., 20, 55-70 (1977)

[2] Nerin, C., Alfaro, P., Aznar, M., \& Domeño, C., Anal. Chim. Acta, 775, 14 (2013)

[3] Reza, J., Trejo, A., \& Elena Vera-Ávila, L. Chemosphere, 47, 933-945 (2002)

[4] Ishak, H., Mokbel, I., Saab, J., Stephan, J., Paricaud, P., Jose, J., \& Goutaudier, C., J Chem Thermodyn, 131, 286-293 (2019)

[5] Mackay, D., Physical-chemical Properties and Environmental Fate Organic Chemicals (2006) 